\title{
The Application of Mirco Elements in Painting
}

\author{
Limin Ruan \\ Institute of Micro-science Arts \\ South China University of Technology \\ Guangzhou, China 510006
}

\author{
Weihai Zhang \\ Institute of Micro-science Arts \\ South China University of Technology \\ Guangzhou, China 510006
}

\begin{abstract}
With the development of the society, science and technology are developing rapidly. Painting records reality from the beginning. But now it breaks away from the shackles of "reproductive art", allowing painters to freely depict. And painting is no longer limited to macro things. With the emergence of advanced physical amplification instruments, people use physical methods to magnify objects, and people begin to view things in different ways. Painters are no longer confined to the macro world, but gradually begin to pay attention to the micro world, and micro elements are gradually used in painting. Entering the new area of modern science and technology, all industries are interconnected and science and technology are used in all aspects of life. The interception and extraction of microscopic elements became easier and it had fundamental changes. In traditional painting, the object of painting is generally macroscopic, and modeling and color are particularly important while the micro world and painting materials have been hidden behind the scenes. Painters began to seek new inspiration, and micro elements were gradually applied to painting. The color, shape, structure, texture richness and refreshment of the microcosmic world are presented by the painter in the form of painting language, so that people can see the brand-new artistic language. Studying the micro world deeply, combined with own creation, extract the microcosmic elements for artistic conception, and use comprehensive materials to show its texture, so as to inject new blood into art.
\end{abstract}

Keywords-micro elements; painting; texture; structure and shape

\section{INTRODUCTION}

Nowadays, with the rapid development of society, the gradual development of science and technology, the development of physical amplification instrument technology is more and more mature. People use physical amplification to re-examine the world. It is no longer confined to the beautiful things in the macro world, also the micro world is more and more popular.

Based on the research background of micro-elements, this paper explores the beauty of micro-elements in painting in terms of color, texture, light, space and composition and so on, which fully reflects the characteristics of microelements. Through the analysis of color texture and structure form of micro-elements, the definition of micro-art is developed and redefined. And through artistic experience, artistic conception and artistic communication, it explores the application of micro-elements in painting. Through advanced scientific instruments for artistic experience, extract accidental, natural, conscious micro-morphology, color, texture for artistic creation, using different painting techniques splash, sprinkle, throw, drop, bullet for painting, summed up how to use micro-elements in painting.

\section{THE CONCEPTION AND DEVELOPMENT OF MiCRO ART}

\section{A. The Significance of Topic}

At present, the theoretical research on the application of micro-elements in painting is still very limited at home and abroad. Most of the micro-elements used in painting are only at the level of basic techniques, texture characteristics, and forms of expression and so on, without theoretical summary, induction and combing, it does not systematically and comprehensively explore this problem as a theory. This article will discuss the artistic beauty of secondary creation by using micro-elements from the application of materials, the intervention of science and technology, the dissemination of information and the transfer of images.

Microorganisms appeared on the earth hundreds of millions of years earlier than human beings. At present, there are many kinds and quantities of microorganisms in the world. After billions of years of evolution of natural selection, microbiology and macrobiology are both having reasonable structure, perfect material metabolism and reuse system, precise self-regulation and coordination capabilities. The uniqueness of microorganisms is worthy of human understanding and learning.

Painting should not be confined to the macro world. It is inevitable for painting to diversify. The complexity of the micro world is no less than that of the vast universe. It is said that "one sand, one world, one leaf and one Bodhi" is not a lie. Small and insignificant ants and a pile of sand becomes a desert, rocks become mountains, and water droplets become ponds. In detail, it seems that chemistry, material science, medicine, physics and so on, which have nothing to do with painting, have great and hidden artistic value in corners and places that people do not pay attention to and hard to touch. The artist's exploration of the microcosmic world has just begun. From the microcosmic perspective, he shows people different works of art. These works shocked the audience no longer by their precise shape and delicate depiction, but by striking at the color, shape and texture that people had never seen before. 
Another discovery and redefinition of micro painting created more possibilities. Painting has infiltrated into various fields, making the meaning of painting richer, the disciplines communicate with each other, and the fields merge with each other. The eyes that discover beauty are not only artists; they may be chemists, biologists, mineralogists and so on. They have become artists in various fields, adding interest to their work, but also bringing infinite possibilities to the innovation and development of micro-painting.

\section{B. The Development of the Status at Home and Abroad}

Nowadays, micro elements are widely used in the art works of bionic design. Many famous micro elements in architecture are presented to the audience. Most of these micro elements are extracted from chemistry, materials science and biology, making architecture more logical and harmonious. Micro design is getting more and more attention from designers, such as the famous water cube national swimming center. The biggest feature is the use of water cube membrane structure to build a landmark spatial structure form. The application of micro elements in design is relatively common, but it is relatively unknown in the field of painting. Therefore, this study focuses on the innovation of micro elements in painting, and it is very necessary to study the depth and breadth of the application of micro elements in painting.

\section{Method of Study}

Through studying the famous works, academic papers, theoretical reports, famous periodicals, paintings and so on about the application of micro-elements in various fields, collecting and analyzing them. Also analyze conclude and summarize the related interesting painting, compare the micro-element paintings with traditional paintings in order to provide a theoretical basis for the application of microelements in painting creation. Finally, it makes a tentative plan for the application of micro-elements in painting, ponders on the future direction and artistic value, and puts forward personal suggestions and opinions.

\section{THE CONCEPT AND ClASSIFICATION OF MiCRO ART}

\section{A. Definition of the Concept}

The literal definition of "micro" is "small" as opposed to "macro". "Small" cannot be measured in detail, and even cannot be found by the naked eye. Therefore, "micro" has hidden meaning. In natural science, it is generally defined by the naked eye. From the perspective of the size of the mass, it is difficult for the naked eye to detect the objects that need to be magnified by physical methods, which is called microscopic.

The definition of traditional micro-art can be summarized as: exquisite, ingenious, is a fine and subtle art, through the artist's vision and touch to complete the works of art. With the development of science and technology, these mysterious and magnificent scenes, which are beyond the reach of human beings, have become accessible. Micro-art once again shocked people's eyes, it was redefined, with the help of physical enlargement tools, from the micro to capture, extract the material form, color, texture, structure and other secondary artistic creation.

\section{B. Classification of Micro Art}

Micro plant world: Animals and plants in the microworld refer to small objects visible to the naked eye, such as honey-picking by bees, ants moving, mosquito bites and so on, which are small and visible activities of the micro-world of animals and plants. When people use the tools of physical magnification to observe and record, they will find that they are very similar to the human way of life. They all have reasonable structure, precise self-coordination, regulation and team cooperation capabilities, which are closely related to human life. Their living environment and way is a diminished version of the human world. When people observe them in different ways, they find it is a flower, a grass and a world.

Microbial world: Microorganisms are usually invisible or invisible to the naked eye. They need physical amplifier to see clearly. They refer to a large group of organisms including bacteria, viruses, fungi and some small protozoa, micro-algae, etc. They are small and closely related to human beings. Their various forms and structures are strange, rich in color, complex texture and so on, capturing a moment, intercepting a picture, providing a good material for artistic creation.

Mineral world: Minerals are chemical compounds and natural elements in the earth's crust. People can see their appearance directly or enlarge them with advanced scientific instruments to observe their internal structure, shape, color and texture, thus revealing the magical mineral world.

Chemical world: Chemicals refer to pure substances and mixtures made up of elements. There are 7 million chemicals in the world in such a large number that it can be seen that there are many kinds and complex varieties. Chemicals may seem to have nothing to do with art, but their structure, shape, color and texture are beautiful.

\section{How to Apply Micro Elements to Painting}

Modern micro-painting is a combination of painting and micro-world, which is applied to many disciplines such as chemistry, biology, aesthetics, and color theory and knowledge system. Micro-paintings mainly study the shape, color, function, structure and other characteristics of matter in nature, and consciously use the characteristics of these micro-elements. It can inspire painting inspiration and provide new thinking and objects for painting.

Micro painting is mainly to change people's way of looking at the world, not only in material, micro painting is more to pursue spiritual things. It pursues the integration and innovation of various elements such as human and nature, different fields and rationality and sensibility, showing an aesthetic view of harmonious coexistence between human and nature. 


\section{A. Extraction of Its Shape}

1) With the development of science and technology and advances in scientific instruments, people can observe the morphological structure of micro-structure with the help of various scientific instruments of physical amplification, and the morphological structure of visual beauty has been paid more and more attention. As shown in "Fig. 1", sheer hills cover the green ground and are well-proportioned with a pleasant color. It seems to be a delicate inset but it is the surface of indium phosphide magnified 1,000 times. As shown in "Fig. 2", a white fish swims freely in the deep blue sea. In reality, it is the crystal obtained after the evaporation of magnesium sulfate and tartaric acid solution magnified 50 times.

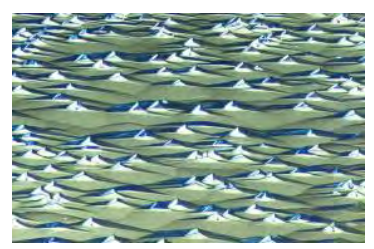

Fig. 1. Author: Ulrich Büttner.

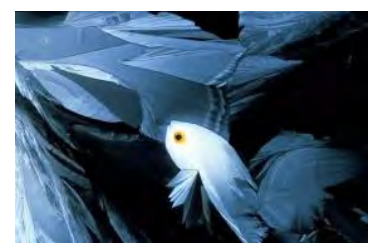

Fig. 2. Auhtor: Richard H.Lee.

$$
{ }^{\text {a. }} \text { Figure source: www.sohu.com }
$$

\section{B. Extraction of Its Color}

Color is an indispensable art language for painting. The color imitation of micro paintings is mainly used for color painting by studying the excellent color functions and forms of natural biological systems. Through the study of the color of micro elements and their color matching form, and the excellent part of them through induction, summary and reference to apply to the painting of a painting method. The most intuitive painting technique of micro element painting, people can see the color of a painting very intuitively. Color has a variety of functions for creatures in nature, such as decoration, camouflage and warning. After countless years of evolution, the layout of structure, function and color has been very perfect, and the color selection and collocation of most of the creatures are very reasonable and ingenious. We should observe more, study more, learn the form of color matching, and show the beauty of biological color to the works. Shown in "Fig. 3", shows the towering rocks, leptosomic red land, cloud of smoke, and the blue sky behind the form sharp contrast, this looks like a abstract paintings, Kandinsky, in fact, Brazil agate goethite and hematite in $30 \mathrm{x}$ magnification, colorful, composition is reasonable, that is the power of the micro elements in painting. As shown in "Fig. $4 "$, the green river water, like the Nile of Egypt, and the landscape of the golden mountains, is actually 50 times larger than the mutual solution of emodin and urea.

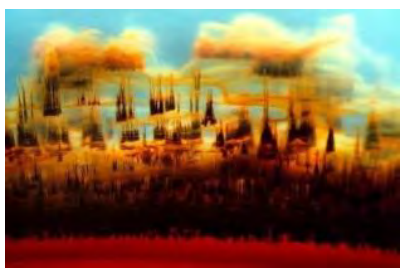

Fig. 3. Author: John I. Koivula.



Fig. 4. Auhtor: Lars Bech $\backslash$.

Figure source: www.sohu.com

Gaëlle de Laveleye is a Belgian artist covering graphic design, painting, sculpture and sculpture. As shown in figure 1-7-8, her art research focuses on the collision between micro and macro, movement and static, individual and ordinary. Starting with the shape of the human body, and taking inspiration from its internal existence, organ composition and molecular structure, explore the fragile connections between all these entities. She has also made remarkable achievements in painting and sculpture.

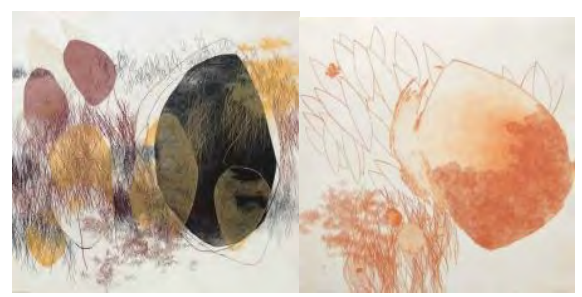

Fig. 5. Author: Gaëlle de Laveley.

Figure source: www.myxy.com.cn

\section{THE APPLICATION OF MiCROSCOPIC ELEMENTS IN PAINTING}

\section{A. Art Experience}

Artistic experience is the experience activity of artists before creation, which is a long-term preparation stage. It refers to the feelings, observations and thoughts of artists on life, as well as the premise and foundation for the formation of artistic creation. Artistic experience in micro-art requires artists to observe, appreciate, extract and capture images that are helpful to their own creation with the help of physical magnification. Micro elements come in various forms. They may be microorganism, mineral substance, chemical products, etc. Everything that can cause emotional fluctuations in the creator will be processed, analyzed and thought by the creator, and then be expressed through artistic creation. I have observed the morphology of nerve cells and 
osteoclasts, and I love the colors of John 1. Koivula's abstract kandinsky paintings and Lars Bech landscapes.

\section{B. Artistic Conception}

There are many ways and forms of artistic conception. The more rich the life experience of art creators is and the more perfect their knowledge reserve, the more creative the artistic conception will be. Then, in a new field of art research, art creators should carry out artistic conception by analyzing, thinking and processing the micro elements they have acquired in the early stage, and then express the thoughts they want to express. Through artistic conception, the morphology of nerve cells and osteoclasts, as well as John 1 Koivula's abstract kandinsky painting and the colors of Lars Bech landscape works are integrated into their own images, which are represented by painting with integrated materials.

\section{Artistic Representation}

Artistic communication refers to the use of certain materials to express the rich and profound feelings of the heart into things for people to appreciate. In addition, preliminary draft composition is made according to the objects observed by oneself and the micro materials intercepted by oneself, which enriches the elements of the picture, unifies the colors of the painting and highlights the thoughts expressed. PS software can also be used to split, shatter, analyze and recombine the two-dimensional creation, to achieve the two-dimensional reconstruction of the image in my mind. By applying the micro elements to the painting, the color, texture, light, space and composition of the micro elements can fully reflect the beauty of the micro elements. It also need to record more micro elements through own experiments, and the possibility of more diversified writing techniques in reality.

1) Color arrangement: A richer visual effect can be achieved through color matching. Successful cclour collocation should accomplish harmonious and comfortable not only, have administrative levels feeling even, rhythm feeling, give a person to enjoy with the United States. As shown in "Fig. 6", the colors of goethite and hematite in agate of Brazil were extracted and magnified 30 times. The preliminary manuscript was made to determine the warm and cool colors of the picture. Then, the paper was used to add turpentine or toner oil and water to make a large-tone overlay and color matching.

2) Texture making: After finishing the collocation, make the texture again. Texture fabrication needs to refer to the morphology of nerve cells, understand the characteristics of materials, and show the advantages of materials and the morphology of cells. Experience and continuous testing of materials directly affect the level and height of works.

Turpentine and propylene are insoluble when water is added. Turpentine will push propylene pigments away and make them feel like bubbles. The toning oil is thicker and the air bubbles are smoother, but it is not easy to dry quickly.
Use the soft properties of fresh-keeping film to mimic the morphology of nerve cells, as shown in "Fig. 7".

In this process, you can match the basic tones, and you can continue to overwrite them if you are not satisfied.

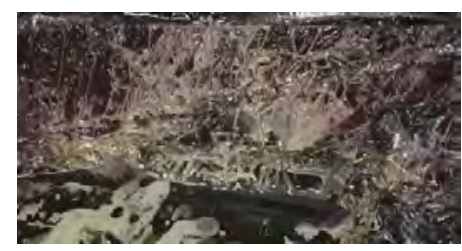

Fig. 6. Use plastic wrap to make texture.

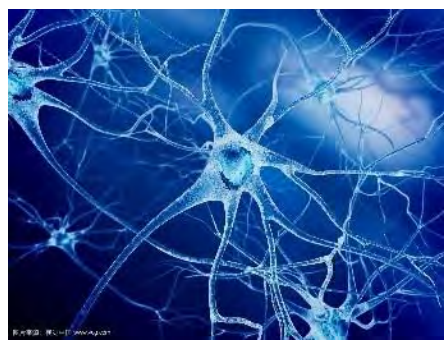

Fig. 7. The morphology of nerve cells.

3) Creative techniques: The comprehensive material painting is different from the traditional painting not only the material, it advocates to apply the real life things to the painting. Based on the background of oil painting creation, this paper studies the color, texture, light sense, space and composition of comprehensive materials in oil painting creation, which fully reflects the beauty of materials. It also need to record more creative techniques through own experiments, and the possibility of more diversified creative techniques in reality.

Pour, sprinkle, throw, drop, etc., all of which are relatively common in the painting of comprehensive materials. This kind of painting method and "action" are same, happy and optional, the unconscious moment is the creator's experience and feeling. This way and a stroke of painting are more flexible, relaxed, it is an enjoyment.

In the process of continuous testing, the technique of "playing" is constantly applied to the picture. After adjusting the paint, use the fan to press on the edge of the disposable bowl and bounce it onto the screen. The closer the distance is, the bigger the pigment particles are.

After the basic techniques are completed, the picture will be unified into a series in order to control the picture. This requires the coordinated operation of the previous steps, the adjustment of the big picture, the uniform color system, and the determination of the tone of heating and cooling. At this stage, the picture is basically a complete picture, as shown in "Fig. 8" and "Fig. 9". 


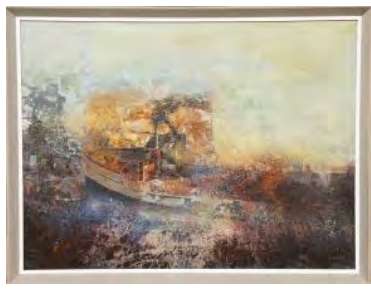

Fig. 8. A complete painting.

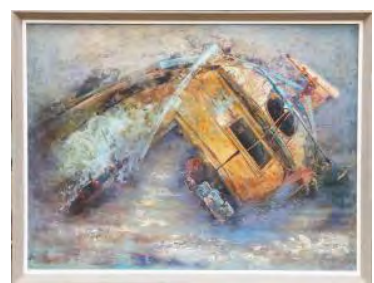

Fig. 9. A complete painting.

Figure source: Limin Ruan

\section{CONCLUSION}

Based on the application of micro elements in painting, this paper studies the structure, shape, color, texture, light sense, space and composition of different micro elements, fully reflects the beauty of micro materials and applies them to painting. The micro world is as profound as the macro world, providing endless materials and inspiration for art. The sense of rhythm that microcosmic element shows, showed the tension of a kind of life adequately, let a person see the form force that macroscopic world cannot see. The micro world is a part and basis of the macro world. The micro world and the macro world are relatively unified, interdependent and interrelated. Studying the micro world can let us see the origin of life, the nature of life, and thus generate thoughts about life and life, which are very important for designers. Only close to life, to live, to feel life will produce shocking works.

Although this paper has done some research on the application methods of micro-elements in painting, there are still many deficiencies, which cannot be further studied and more in-depth discussion, but can only be done some research. I hope that artists will have in-depth discussions on the study of micro-elements in painting, and apply microelements in various fields to painting to create different visual work.

\section{REFERENCES}

[1] Shurong Wang. Inspiration of nature [M]. Shanghai: Shanghai science and technology press, 1978.6. (in Chinese)

[2] Weifeng Bao. A brief analysis of the texture of painting: how to interpret the language elements of modern painting [J]. Journal of lishui university, 2005. (in Chinese)

[3] Alan powers. Natural design [M]. Wang lifei, et al., translation. Nanjing: jiangsu fine artsPress, 2001.6:165-166. (in Chinese)

[4] Yiping Hu. Yong Li, Quan Liu. Aesthetics of texture materials - on the value orientation of comprehensive material painting texture $[\mathrm{J}]$. Journal of chaohu college, 2002, 4(2). (in Chinese)
[5] Liangzhi Li. Color design qiao [M]. Beijing. Advanced education press, 2006.6: 25-26. (in Chinese)

[6] Shengzhong Lu. Original shape [M]. First edition. Sanlian publishing. 1992.1: 178. (in Chinese)

[7] Weihai Zhang.Meiling Qiu. Artistry of micro-science [J]. Journal of tianjin academy of fine arts. 2011.3. (in Chinese)

[8] Haijun Shen. Nano art - art invisible to the naked eye [J]. Life world. 2012.3. (in Chinese)

[9] Limi Mao. Look from the pollen micro world of nature's art [J] Knowledge is power. 2009.6. (in Chinese)

[10] Jingguo Zhou. Unlocking the mystery of microcosm -- the scientific process of the invention of microscope [J]. Science 24. 2008.8. (in Chinese) 